\title{
Synaptic loss and amyloid beta alterations in the rodent hippocampus induced by streptozotocin injection into the cisterna magna
}

\author{
Yujin Ahn ${ }^{1,2+}$, Jincheol Seo ${ }^{1,3+}$, Junghyung Park ${ }^{1 \dagger}$, Jinyoung Won ${ }^{1}$, Hyeon-Gu Yeo ${ }^{1,2}$, Keonwoo Kim', \\ Chang-Yeop Jeon ${ }^{1}$, Jae-Won Huh ${ }^{1,2}$, Sang-Rae Lee ${ }^{1,2}$, Dong-Seok Lee ${ }^{3}$ and Youngjeon Lee ${ }^{1 *}$ (D)
}

\begin{abstract}
To date, researchers have developed various animal models of Alzheimer's disease (AD) to investigate its mechanisms and to identify potential therapeutic treatments. A widely recognized model that mimics the pathology of human sporadic AD involves intracerebroventricular (ICV) injection with streptozotocin (STZ). However, ICV injections are an invasive approach, which creates limitations in generalizing the results. In this study, we produced a rodent model of AD using STZ $(3 \mathrm{mg} / \mathrm{kg}$ ) injection via the cisterna magna (CM) once every week for 4 weeks, and analyzed at 4 weeks and 16 weeks after final injection. In the CM-STZ rodent model of AD, we observed increase in extracellular amyloid-beta (A $\beta$ ) deposition and decrease and abnormal morphology of post-synaptic protein, PSD95 in 16 weeks STZ-injected group. The model developed using our less-invasive method induced features of AD-like pathology, including significantly increased extracellular amyloid-beta deposition, and decreased synaptic protein in the hippocampus. These findings supporting the success of this alternative approach, and thus, we suggest this is a promising, less invasive model for use in future AD research.
\end{abstract}

Keywords: Alzheimer's disease, Streptozotocin, Cisterna magna

\section{Introduction}

Alzheimer's disease $(\mathrm{AD})$ is the most common neurodegenerative disorder causing dementia $[1] . \mathrm{AD}$ is pathologically characterized by amyloid-beta $(A \beta)$ plaques, neuronal loss, and cognitive impairment [2]. Considerable research has been performed to develop $\mathrm{AD}$ models and conduct preclinical studies to investigate the mechanisms underlying $\mathrm{AD}$ and potential treatment options [3].

* Correspondence: neurosci@kribb.re.k

${ }^{\dagger}$ Yujin Ahn, Jincheol Seo and Junghyung Park contributed equally to this work

${ }^{1}$ National Primate Research Center, Korea Research Institute of Bioscience and Biotechnology (KRIBB), Cheongju 28116, Republic of Korea

Full list of author information is available at the end of the article
Streptozotocin (STZ) is a diabetogenic compound able to induce insulin-resistant cells similar to sporadic AD neural cells [4]. Therefore, intracerebroventricular (ICV) injection with STZ is used to mimic the pathology of human sporadic AD [5]. However, a major disadvantage of this method is the invasiveness of the ICV injection, which involves craniotomy and directly damages the brain tissue. A previous paper confirmed accurate and reproducible access to the artificial cerebrospinal fluid (aCSF) of rodents using a cisterna magna (CM) injection method [6]. Furthermore, the injected molecules diffused into the parenchyma, similar to diffusion following ICV injection [7].

In the present study, we produced a rodent model of $\mathrm{AD}$, using $\mathrm{STZ}$ injection via the $\mathrm{CM}$ and determined the development of AD-like pathologies. It was found that this

(c) The Author(s). 2020 Open Access This article is licensed under a Creative Commons Attribution 4.0 International License, which permits use, sharing, adaptation, distribution and reproduction in any medium or format, as long as you give appropriate credit to the original author(s) and the source, provide a link to the Creative Commons licence, and indicate if changes were made. The images or other third party material in this article are included in the article's Creative Commons licence, unless indicated otherwise in a credit line to the material. If material is not included in the article's Creative Commons licence and your intended use is not permitted by statutory regulation or exceeds the permitted use, you will need to obtain permission directly from the copyright holder. To view a copy of this licence, visit http://creativecommons.org/licenses/by/4.0/. The Creative Commons Public Domain Dedication waiver (http://creativecommons.org/publicdomain/zero/1.0/) applies to the data made available in this article, unless otherwise stated in a credit line to the data. 
model successfully induced AD-like pathological features, such as extracellular $A \beta$ accumulation and synaptic loss.

\section{Materials and methods}

Experimental animals

Male Sprague Dawley rats $(460 \pm 20$ g, 14 weeks old) were housed in a temperature-controlled room $\left(20-23^{\circ} \mathrm{C}\right)$ with $30-60 \%$ humidity in a 12-h light-dark cycle with ad libitum access to standard food pellets and water. All procedures were approved by the Korea Research Institute of Bioscience and Biotechnology Institutional Animal Care and Use Committee (Approval No. KRIBB-AEC-18016).

\section{CM injection of STZ and brain sampling}

For CM injection of STZ, we used a needle-tubing assembly that comprised of PE10 and PE50 tube tubing, 27G dental needle, PE10/PE50 tubing connector and 22G Hamilton syringe (Fig. 1b) The rats were anesthetized with $3 \%$ isoflurane in an induction chamber and maintained under isoflurane anesthesia at $2 \%$ during injection. STZ (Sigma-Aldrich, St. Louis, MO, USA) was dissolved in aCSF and was infused into the CM at a rate of $10 \mu \mathrm{l} / \mathrm{min}$ $(10 \mu \mathrm{l}$ total volume, final dose $3 \mathrm{mg} / \mathrm{kg}$ ). The needle was maintained in place for $1 \mathrm{~min}$ after injection. Rats received injections once every week for 4 weeks, before being sacrificed for analysis at acute (4 weeks) and chronic (16 weeks) time points (Fig. 1a). For tissue sampling, rats were anesthetized with $30 \%$ urethane and transcardially perfused with phosphate-buffered saline (PBS). The brain was dissected, and the hemisphere was used for immunohistochemistry and western blot analysis, respectively.

\section{General health monitoring}

Body weight was recorded weekly prior to injections. Blood glucose levels were measured using Accu-Chek ${ }^{\circ}$ Guide meter (Roche, Basel, Switzerland) on the 4 and 16 weeks after the first STZ injection.

\section{Immunohistochemistry}

The hemisphere was fixed in $10 \%$ neutral buffered formalin for 2 days at $4{ }^{\circ} \mathrm{C}$. After dehydrating with $30 \%$ sucrose, the tissues were embedded in optimal cutting temperature compound, and transverse sections $(30 \mu \mathrm{m})$ were serially cut using a cryostat. The sections were then placed in $88-91 \%$ formic acid for antigen retrieval of $A \beta$. After blocking using 4\% normal horse serum for $2 \mathrm{~h}$, sections were incubated overnight at $4{ }^{\circ} \mathrm{C}$ in diluted primary antibody for $\mathrm{A} \beta$ (6E10; Novus, Plainsboro, NJ, USA) and PSD95 (Abcam, Cambridge, MA, USA). Sections were then incubated with biotinylated anti rabbit-IgG secondary antibody (Vector Laboratories, Burlingame, CA, USA). The sections were stained with DAB (3,3'-Diaminobenzidine; Vector Laboratories).

\section{Western blot analysis}

The hippocampus was harvested from the hemisphere and homogenized in RIPA buffer (Thermo Scientific, Waltham, MA, USA). Proteins lysates were loaded onto

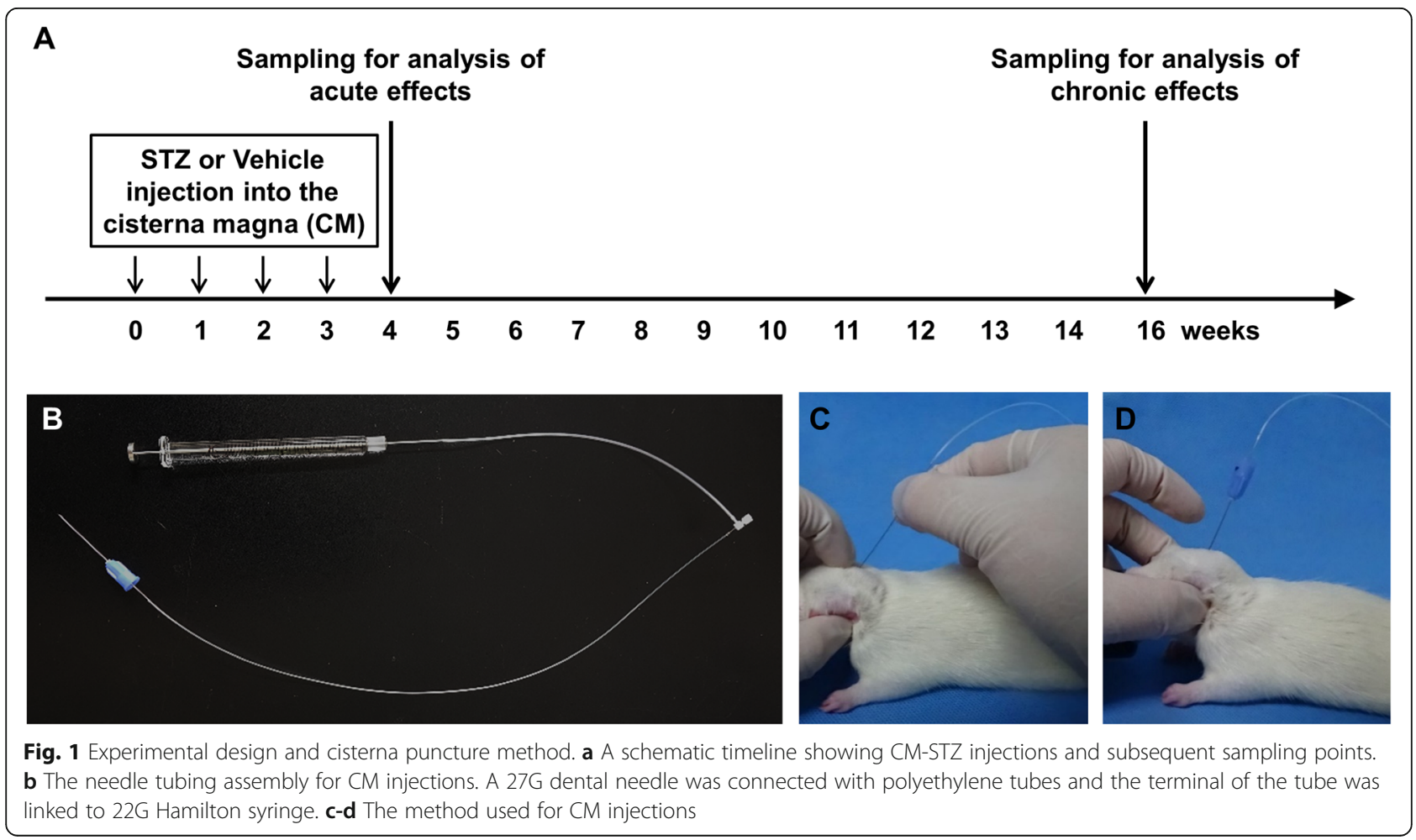


10-16\% SDS-PAGE gels, transferred to nitrocellulose membranes and blocked with blocking buffer (BD Biosciences, Franklin Lakes, NJ, USA). Membranes were incubated at $4{ }^{\circ} \mathrm{C}$ overnight with primary antibodies against PSD95 (Abcam) and $\beta$-actin (Sigma-Aldrich). Following washing with TBST (tris-buffered saline with $0.1 \%$ tween 20), the membranes were incubated with secondary antibodies (Cell Signaling, Danvers, MA, USA) for $1 \mathrm{~h}$ at room temperature. Specific binding was detected using a chemiluminescence detection system (Bio-Rad, Hercules, CA, USA).

\section{Statistical analysis}

The data represent the mean and standard deviation (SD) from three independent experiments $(n=3)$.
Statistical significance was determined using two-way analysis of variance (ANOVA) conducted by GraphPad Prism 5 software (San Diego, CA, USA).

\section{Results}

Change in body weight and blood glucose by CM-STZ

Body weight was reduced in the STZ-injected group when compared to the aCSF-injected group until 4 weeks. However, after the final injection, body weight appeared to recover, with no significant difference between the STZ-injected group and control animals by 8 weeks (Fig. 2a). To analyze the effect of STZ on metabolism, we measured blood glucose level at random or in a fasting state at week 4 and 16 . There was no significant

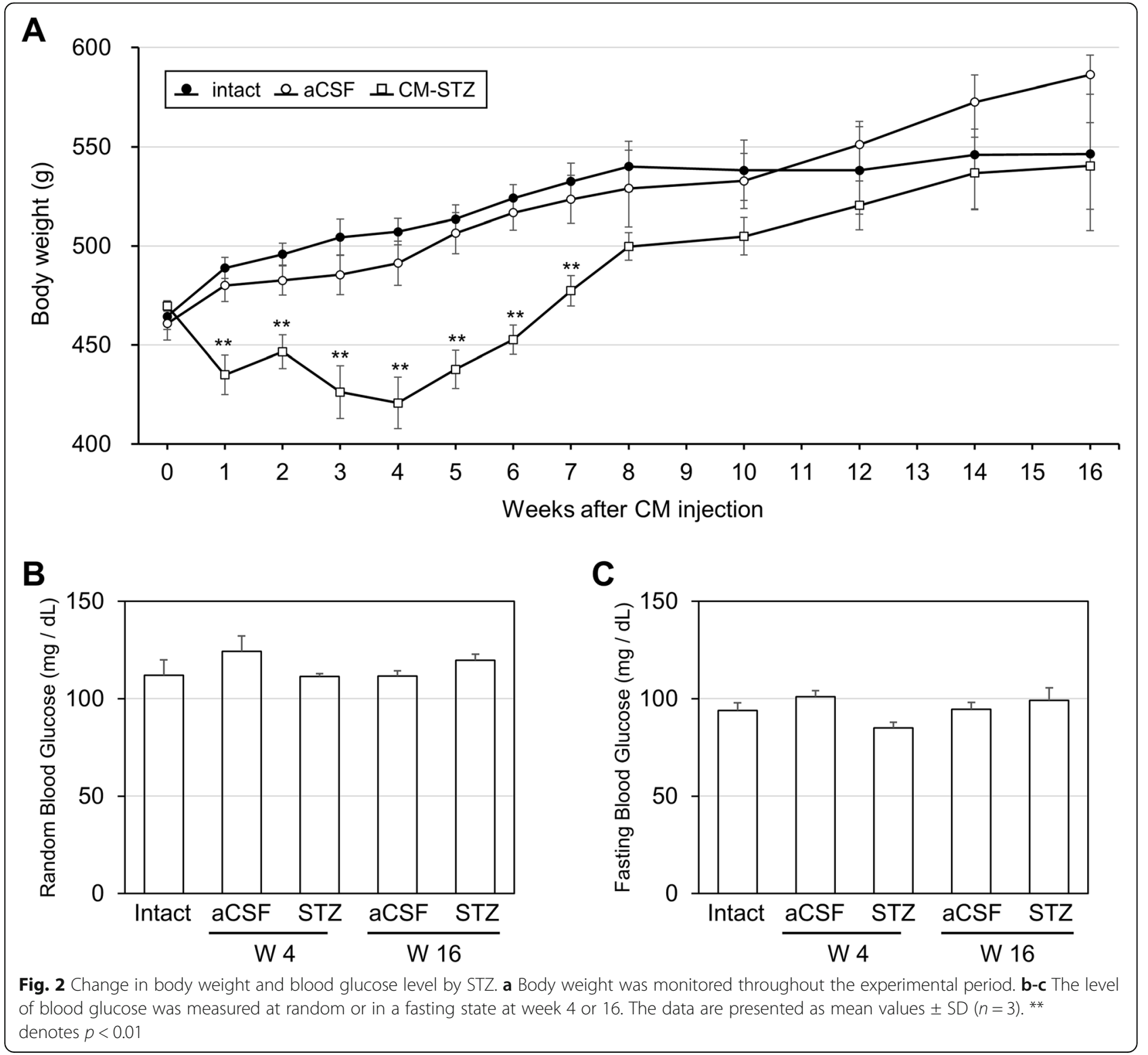


alteration in the average blood glucose level between aCSF- and STZ-injected groups (Fig. 2b and c).

\section{CM-STZ induced extracellular $A \beta$ accumulation and synaptic loss}

To confirm the presence of $A \beta$ accumulation in CMSTZ model, we performed immunochemistry using an $A \beta$ (6E10) antibody in CA3 of the hippocampus. $A \beta$ accumulation was observed outside of the cells and was increased in the STZ-injected group at 16 weeks (Fig. 3). In addition, we analyzed the expression of the postsynaptic protein PSD95 by western blotting and immunohistochemistry. Although expression levels of PSD95 in the hippocampus were not altered at 4 weeks in the STZ-injected group, a significant decrease was observed at 16 weeks when compared to controls (Fig. 4a and b). Moreover, the morphology of synapse was abnormal in STZ-injected group (Fig. 4c). These results suggest that AD-like pathologies were induced by CM-STZ injection.

\section{Discussion}

A common model of sporadic AD involves a ICV-STZ injection [8]. However, ICV injection is an invasive procedure involving skin incision and trauma to brain tissue, which can bring the reliability of results into question. Therefore, we proposed that $\mathrm{CM}$ injection would be equally effective at inducing $\mathrm{AD}$ and overcome some limitations of the ICV model. The current study provides evidence that using the $\mathrm{CM}$ as an alternative

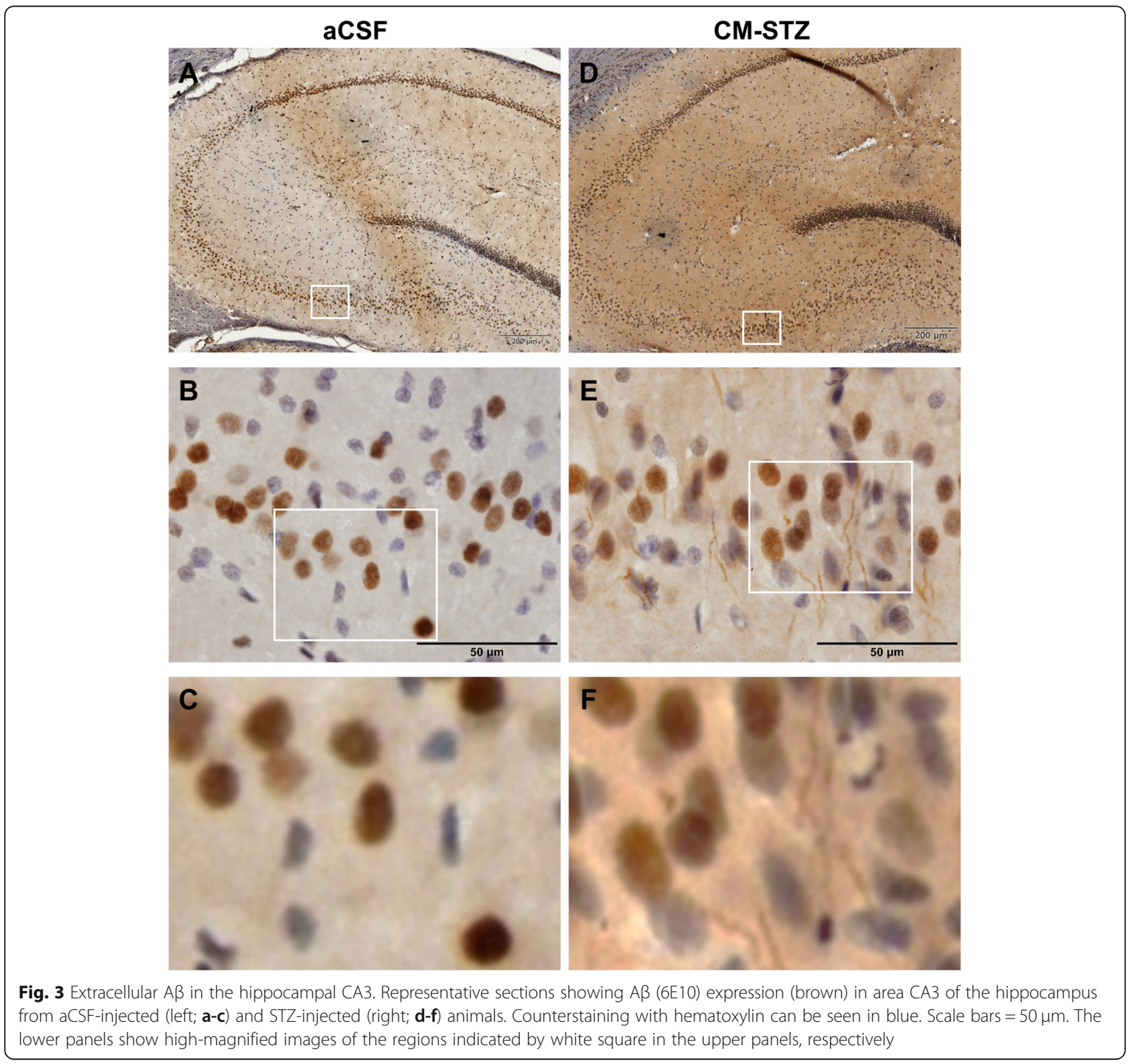




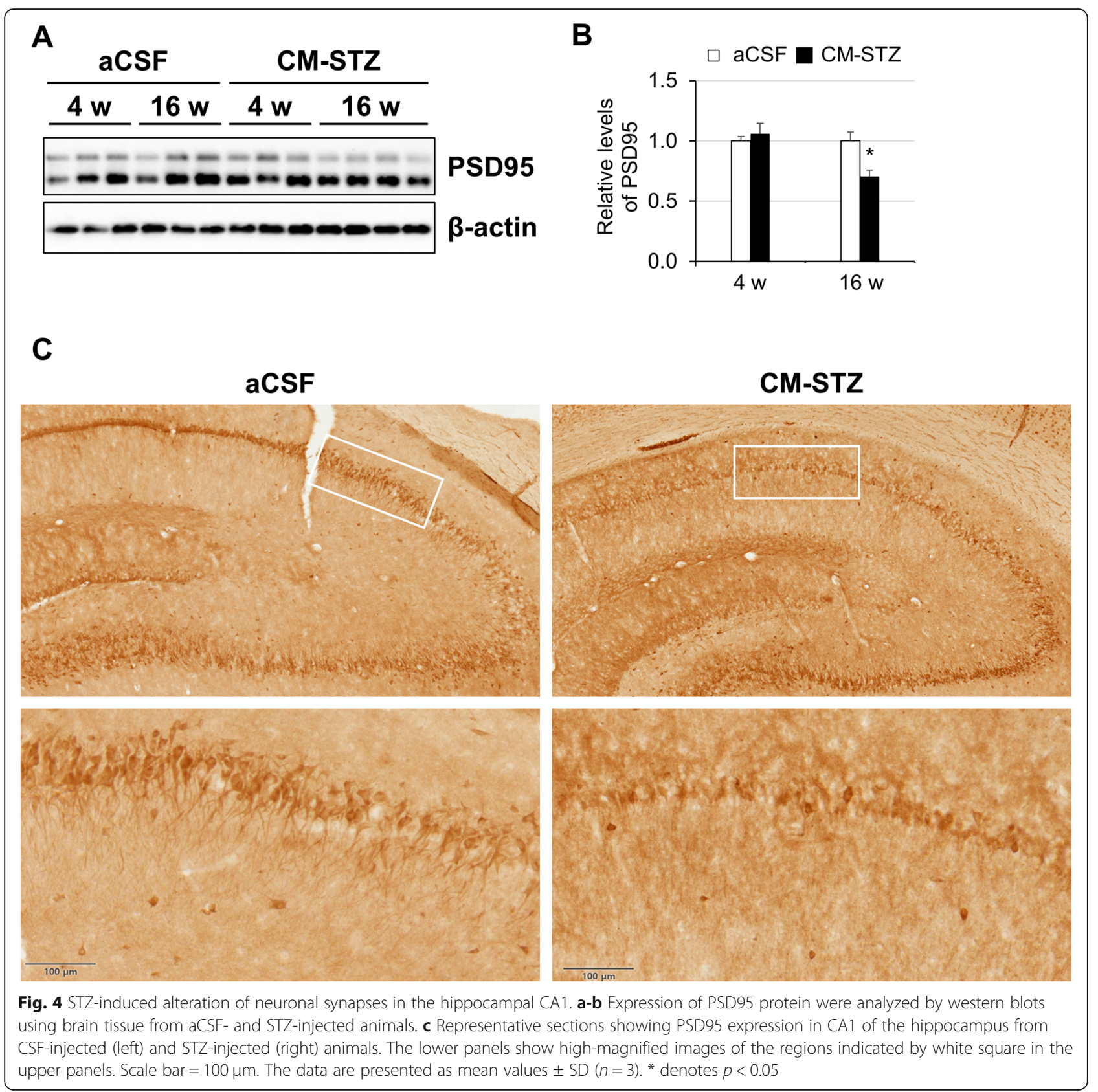

site of STZ injection is indeed effective at producing key pathological features of sporadic $A D$ in a less invasive manner.

One key pathological finding was the increase in extracellular A $\beta$ and synaptic loss in the CM-STZ model. A previous study has shown that intracellular $A \beta$ accumulation is increased 3 months after ICV-STZ injection, and that $\mathrm{A} \beta$ plaques are detectable at 6 months [9]. We did not see plaques in our CM-STZ model, however our study only extended to 4 months post-STZ injection and we did observe an increase in extracellular $A \beta$ at this time point.
Furthermore, PSD95 was reduced in the hippocampus by CM-STZ injection after 16 weeks, but not at 4 weeks. Decreases in the expression of post synaptic protein PSD95 are associated with a decline in learning and memory function [10], so this corresponds to pathological changes associated with the development of $\mathrm{AD}$ in our model.

Loss of body weight is a common characteristic in $\mathrm{AD}$ patients and ICV-STZ rodents have also been shown to lose weight without experiencing any change in blood glucose [11]. In our study, CM-STZ caused weight loss during the injection period, which recovered to control 
levels following the last injection, with no alteration in blood glucose.

An additional benefit of CM-STZ injection model is the ability to administer many injections over time, due to the reduced invasiveness of the procedure. In our case, we were able to repeatedly inject STZ into aCSF for 4 weeks. This approach mitigated the effects of STZ clearance during aCSF turnover.

In conclusion, we have demonstrated that our CMSTZ injection method is less-invasive and induces a similar sporadic AD-like pathology to the ICV-STZ injection model.

\section{Conclusions}

We suggest that the method for producing a sporadic AD-like rodent model using less-invasive STZ injection via the $\mathrm{CM}$.

\section{Abbreviations}

aCSF: Artificial cerebrospinal fluid; AD: Alzheimer's disease; Aß: Amyloid-beta; CM: Cisterna magna; ICV: Intracerebroventricular; DAB: 3,3'-Diaminobenzidine; SDS-PAGE: Sodium dodecyl sulfate-polyacrylamide gel electrophoresis; RIPA buffer: Radioimmunoprecipitation assay buffer; STZ: Streptozotocin; TBST: Tris buffered saline with $0.1 \%$ Tween 20

\section{Acknowledgements}

N/A

\section{Authors' contributions}

YA, JS, and JP participated in design of the experiments, performed the experiments, analyzed the data, and drafted the manuscript. JW, H-GY, KK, and C-YJ performed and supported the experiments. J-WH, S-RL, D-SL, and $Y L$ edited and revised manuscript. The authors read and approved the final manuscript.

\section{Funding}

This research was supported by the Korea Research Institute of Bioscience and Biotechnology Research Initiative Program (KGM4621922).

\section{Availability of data and materials}

All data produced or analyzed in the present study are available upon reasonable request.

\section{Competing interests}

The authors declare that they have no competing interests.

\begin{abstract}
Author details
${ }^{1}$ National Primate Research Center, Korea Research Institute of Bioscience and Biotechnology (KRIBB), Cheongju 28116, Republic of Korea. ${ }^{2}$ Department of Functional Genomics, KRIBB School of Bioscience, University of Science and Technology (UST), Daejeon 34113, Republic of Korea. ${ }^{3}$ School of Life Sciences, BK21 Plus KNU Creative BioResearch Group, Kyungpook National University, Daegu 41566, Republic of Korea.
\end{abstract}

Received: 9 January 2020 Accepted: 21 May 2020

Published online: 10 June 2020

\section{References}

1. Xie A, Gao J, Xu L, Meng D. Shared mechanisms of neurodegeneration in Alzheimer's disease and Parkinson's disease. Biomed Res Int. 2014;2014: 648740

2. Pinheiro L, Faustino C. Therapeutic strategies targeting amyloid-beta in Alzheimer's disease. Curr Alzheimer Res. 2019;16(5):418-52.

3. Shineman DW, Basi GS, Bizon JL, Colton CA, Greenberg BD, Hollister BA, Lincecum J, Leblanc GG, Lee LB, Luo F, et al. Accelerating drug discovery for
Alzheimer's disease: best practices for preclinical animal studies. Alzheimers Res Ther. 2011;3(5):28.

4. Correia SC, Santos RX, Perry G, Zhu X, Moreira PI, Smith MA. Insulin-resistant brain state: the culprit in sporadic Alzheimer's disease? Ageing Res Rev. 2011;10(2):264-73.

5. Kamat PK. Streptozotocin induced Alzheimer's disease like changes and the underlying neural degeneration and regeneration mechanism. Neural Regen Res. 2015;10(7):1050-2.

6. Chen $Y$, Imai $H$, Ito A, Saito N. Novel modified method for injection into the cerebrospinal fluid via the cerebellomedullary cistern in mice. Acta Neurobiol Exp (Wars). 2013;73(2):304-11.

7. Proescholdt MG, Hutto B, Brady LS, Herkenham M. Studies of cerebrospinal fluid flow and penetration into brain following lateral ventricle and cisterna magna injections of the tracer [14C]inulin in rat. Neuroscience. 2000;95(2): 577-92.

8. Grieb P. Intracerebroventricular Streptozotocin injections as a model of Alzheimer's disease: in search of a relevant mechanism. Mol Neurobiol. 2016;53(3):1741-52.

9. Knezovic A, Osmanovic-Barilar J, Curlin M, Hof PR, Simic G, Riederer P, Salkovic-Petrisic M. Staging of cognitive deficits and neuropathological and ultrastructural changes in streptozotocin-induced rat model of Alzheimer's disease. J Neural Transm (Vienna). 2015:122(4):577-92.

10. Sultana R, Banks WA, Butterfield DA. Decreased levels of PSD95 and two associated proteins and increased levels of $\mathrm{BCl} 2$ and caspase 3 in hippocampus from subjects with amnestic mild cognitive impairment: insights into their potential roles for loss of synapses and memory, accumulation of Abeta, and neurodegeneration in a prodromal stage of Alzheimer's disease. J Neurosci Res. 2010;88(3):469-77.

11. Zhang $Y$, Ding R, Wang S, Ren Z, Xu L, Zhang X, Zhao J, Ding Y, Wu Y, Gong $Y$. Effect of intraperitoneal or intracerebroventricular injection of streptozotocin on learning and memory in mice. Exp Ther Med. 2018;16(3): 2375-80.

\section{Publisher's Note}

Springer Nature remains neutral with regard to jurisdictional claims in published maps and institutional affiliations.

Ready to submit your research? Choose BMC and benefit from:

- fast, convenient online submission

- thorough peer review by experienced researchers in your field

- rapid publication on acceptance

- support for research data, including large and complex data types

- gold Open Access which fosters wider collaboration and increased citations

- maximum visibility for your research: over $100 \mathrm{M}$ website views per year

At $\mathrm{BMC}$, research is always in progress.

Learn more biomedcentral.com/submissions 